\title{
An investigation of an air-abrasive flow influence on the dynamics of blade steels erosion
}

\author{
A. B. Tkhabisimov, L. I. Seleznev \& A. F. Mednikov \\ Scientific Research Center "Wear Resistance", \\ National Research University "MPEI”, Russian Federation
}

\begin{abstract}
The present work is devoted to the study of the solid particle erosion resistance of steels $20 \mathrm{kH} 13$ and $15 \mathrm{kH} 11 \mathrm{MF}$ applied for manufacturing of the first stages stationary and rotating blades of high and medium pressure cylinders of steam turbines.

The paper describes the experimental rig for the solid particle erosion resistance investigation of structural materials and protective coatings as well as the research's method of varying experimental parameters influence (air-abrasive flow rate and solid particles angle of attack) on the dynamics of the blade steels (20kH13 and $15 \mathrm{kH} 11 \mathrm{MF}$ ) solid particle erosion process.

It has been established that the surface injury (destruction) of the blade steel $20 \mathrm{kH} 13$ and $15 \mathrm{kH} 11 \mathrm{MF}$ samples rises during the solid particle erosion process with increasing of air-abrasive flow rate and reaches its maximum value at attack angles close to $30^{\circ}$.

Keywords: steam turbines, solid particle erosion, blade steels, experimental rig, experimental research, abrasive tracks, profilograms.
\end{abstract}

\section{Introduction}

First stages stationary and rotating blades of high (HPC) and medium pressure cylinders (MPC) of steam turbines are exposed to solid particle erosion (SPE). Solid particles of magnetite $\left(\mathrm{Fe}_{3} \mathrm{O}_{4}\right)$, which arising due to the film exfoliation of scoria from the internal surfaces of superheaters' pipes, drag by steam and interact with blade system surface with different velocities and at different attack angles causing damage and loss of originally designed aerodynamic characteristics. 
Erosive wear of materials under the influence of solid (abrasive) or liquid erodent relates to a very complex process with respect to prediction caused by their statistical nature [1]. Typically, the solid particles have different irregular and rough form, move in the flow of the carrier phase (gas, liquid) in random trajectories and interact with the working surfaces of the power equipment elements with different velocities and at different angles causing injury or wear. Detailed research of the individual stages (periods) of erosion process is far from the final complete and depth: it requires the penetration in physical content of this deeply nonstationary process (in relation to the target material as well as in relation to the material of erodent particles), which is generally polydispersion. As a result, the problem of this process prediction in most cases on the basis of results of detailed and deep analysis of individual stages cannot be solved. Corrosion resistant and heat resistant steels are used for HPC and MPC pressure cylinders first stages blades manufacturing, which relate to martensitic-ferritic and martensitic class as well as metal alloys based on nickel. These are heat resistant and stainless steels (18kH11MFNB, 15kH11MF, 20kH13 etc.), which hold their properties at operating temperatures up to $580^{\circ} \mathrm{C}$, and alloys with a nickel content of more than $65 \%$ (f.e. HN65KMVUB (EP-800-VD)).

The aim of the present work was to study the steel blade SPE process dynamics (f.e. steels $20 \mathrm{kH} 13$ and $15 \mathrm{kH} 11 \mathrm{MF}$ ) by conducting research of the air-abrasive flow rate and attack angle of solid particles influence on its (steel) wear intensity.

\section{Equipment and methods of research}

Conducting research of SPE process by using experimental rigs and benches allows to simulate the processes occurring in the turbines and to investigate the blade materials destruction processes.

In accordance with the standard ASTM G76 in NRU MPEI was created the experimental rig for complex systematic SPE studies of structural materials and coatings damages under the influence of real air-abrasive flow at different velocities, attack angles and target temperatures [2].

Experimental rig technical specifications are shown in Table 1.

Table 1: Technical specifications of experimental rig.

\begin{tabular}{|c|c|}
\hline Parameter & Value \\
\hline Average flow velocity, $\mathrm{m} / \mathrm{sec}$ & up to 200 \\
\hline Attack angle, deg & $10-90$ \\
\hline Sample temperature, ${ }^{\circ} \mathrm{C}$ & up to 600 \\
\hline
\end{tabular}

This experimental rig relates to sand blast type equipment $[3,4]$ and is designed for the following applications:

- simulation of SPE structural materials destruction;

- research of various blade materials and coatings resistance to shock-dynamic impact;

- investigation of the materials and protective coatings destruction dynamics. 
A schematic diagram of the rig is shown in Figure 1.

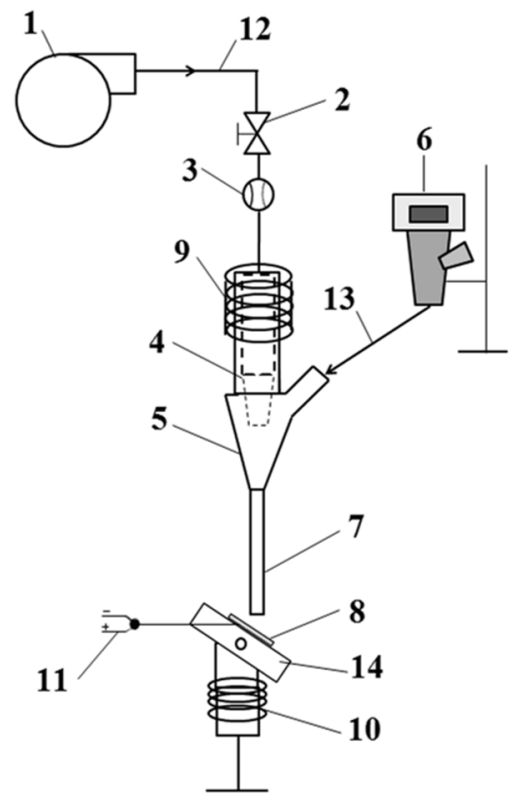

Figure 1: Schematic diagram of the experimental rig: (1) - spiral compressor; (2) - filter-controller; (3) - flow-control unit; (4) - Venturi tube; (5) - mixing chamber; (6) - particles powder feeder; (7) - stabilizing tube; (8) - sample; (9) - spiral heating element; (10) - ceramic heater; (11) - thermoelectric converter; (12) - air supply line; (13) - abrasive supply line; (14) - bracket.

Compressed air from the spiral compressor (1) is supplies to the filtercontroller (2) where is it's cleaning from various suspensions and impurities and pressure reducing. Flow-control unit (3) mounted further on the path uses for monitoring the airflow rate, the value of which determines the flow velocity. Next by the air supply line (12) the flow is accelerated in the Venturi tube (4) and enters the mixing chamber (5).

Abrasive hard particles with a certain flow rate, the value of which controls by particles powder doser (6) software module, enter the mixing chamber by using abrasive supply line (13). After mixing chamber air-abrasive flow exits the stabilizing tube (7) and interacts with the surface of experimental sample (8).

The sample angle with respect to flow axis is controlled by using a graduated scale on the bracket (14). Special rotating part of the bracket allows to regulate the attack angle of air-abrasive flow with respect to the sample surface in the range $10-90^{\circ}$.

Also there is spiral heating element (9) on the air supply line and the ceramic heater (10) for the experimental sample warming, the temperature of which is controlled by a thermoelectric converter (11). 
The experimental sample is a disc with $36 \mathrm{~mm}$ diameter and $3 \mathrm{~mm}$ thickness. Hot-rolled rods of steel $20 \mathrm{kH} 13$ and $15 \mathrm{kH} 11 \mathrm{MF}$ were purchased for their manufacture. Their chemical composition is shown in Table 2.

Table 2: Chemical composition of 20kH13 and 15kH11MF steels.

\begin{tabular}{|c|c|c|c|c|c|c|c|c|c|}
\hline \multirow{2}{*}{ Material } & \multicolumn{10}{|c|}{ Mass fraction, \% } \\
\cline { 2 - 10 } & $\mathrm{C}$ & $\mathrm{Si}$ & $\mathrm{Mn}$ & $\mathrm{Cr}$ & $\mathrm{Ni}$ & $\mathrm{Mo}$ & $\mathrm{Cu}$ & $\mathrm{V}$ & $\mathrm{Fe}$ \\
\hline $20 \mathrm{kH} 13$ & 0.22 & 0.33 & 0.46 & 12.5 & 0.37 & 0.05 & 0.2 & 0.026 & $\mathrm{OcH}$ \\
\hline $15 \mathrm{kH} 11 \mathrm{MF}$ & 0.16 & 0.31 & 0.4 & 10.79 & 0.2 & 0.66 & 0.12 & 0.32 & $\mathrm{OcH}$ \\
\hline
\end{tabular}

The sample's surface was cleaned from possible impurities and dust before each experiment. Research was carried out with a definite time step same for each steel. Before and after each experiment sample was weighed with precision to $0.0001 \mathrm{~g}$ that allowed to evaluate the sample mass remote $\Delta \mathrm{m}$ for definite exposure time on the rig. Also, after each experiment the area of damaged section $\Delta \mathrm{S}$ so-called "abrasive track" was evaluated. Thus, SPE curves represent dependence of the damaged surface mass loss per unit area $(\Delta \mathrm{m} / \Delta \mathrm{S})$ from exposure time on the rig. $\mathrm{Al}_{2} \mathrm{O}_{3}$ (corundum) particles with average size of 250 $300 \mu \mathrm{m}$ are used as erodent particles. Figure 2(a) shows the general view of original erodent particles (before the experiment). Distribution histogram of particles characteristic size (length $\mathrm{I}, \mu \mathrm{m}$ ) is shown in Fig. 2(b) and clearly demonstrates the presence in the original erodent two fractions, i.e. a bimodal distribution.

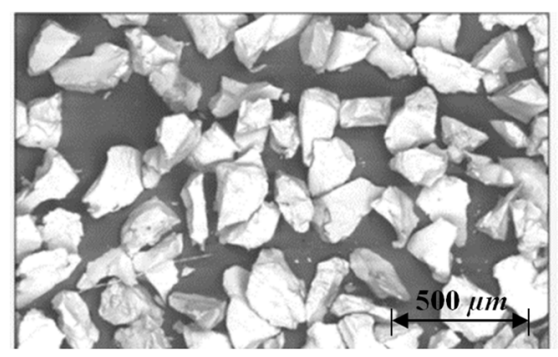

(a)

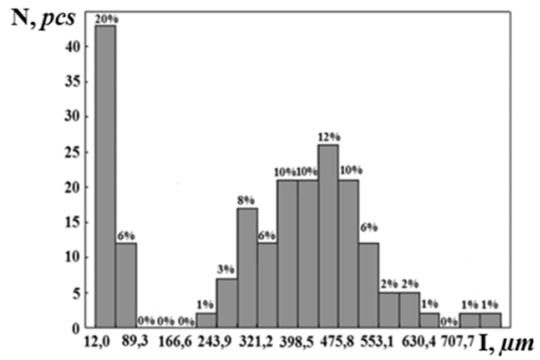

(b)

Figure 2: General view of original erodent (a) and distribution histogram of solid particles size (b).

Profilograms along and across the "abrasive trace" on the samples surface after research were constructed to determine the erosive wear depth depending on the different parameters of the experiment. The scheme of studies is presented in Figure 3. 


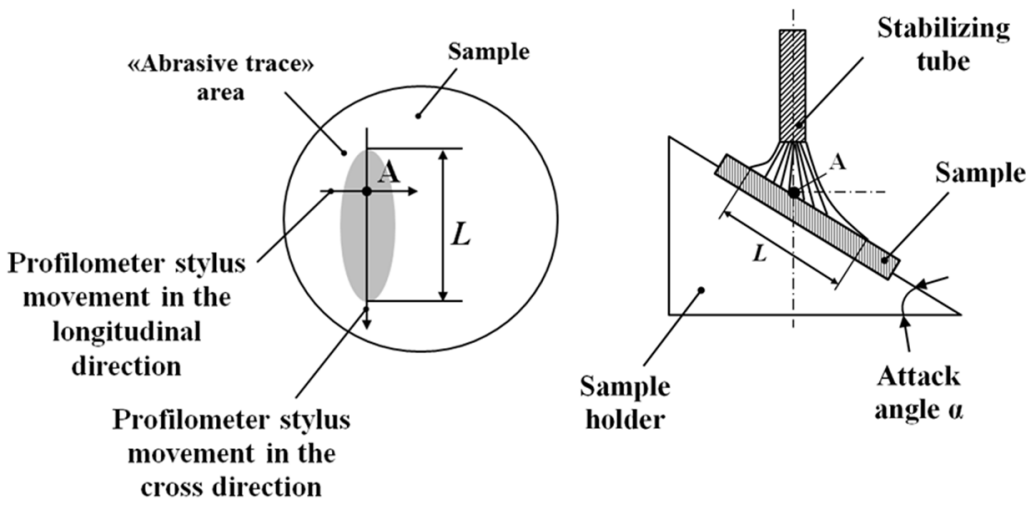

Figure 3: Profilograms measurement scheme in the along and cross directions in the abrasive track field of the sample surface after testing: A - point of the maximum SPE depth value; $\mathrm{L}$ - length of the "abrasive trace".

\section{Experimental results}

Experimental research was performed at different flow rates $\mathrm{G}\left(5.58 \times 10^{-4}\right.$; $\left.4.78 \times 10^{-4} ; 3.88 \times 10^{-4}\right), \mathrm{kg} / \mathrm{s}$ and at different attack angles $(15,30,45,60,90)$, deg. of air-abrasive jet flow with the sample surface. Figure 4 shows the results of experimental research of the air-abrasive jet flow rate influence on the steels $15 \mathrm{kH} 11 \mathrm{MF}$ and $20 \mathrm{kH} 13 \mathrm{SPE}$ intensity.

Unit (with respect to sample damaged section area unit) $\operatorname{SPE}(\Delta \mathrm{m} / \Delta \mathrm{S})$ increases with air-abrasive flow rate $\mathrm{G}$ rising. It should be noted that with flow rate rising weight loss $\Delta \mathrm{m}$ grows individually and the sample damaged section area $\mathrm{S}$ increases individually too.

Figure 5 shows the dependence of unit (with respect to sample damaged section area unit) $\mathrm{SPE}(\Delta \mathrm{m} / \Delta \mathrm{S})$ of selected steels at different attack angles $\left(15^{\circ}, 30^{\circ}, 45^{\circ}\right.$, $60^{\circ}$ and $90^{\circ}$ ) and at the air-abrasive flow rate $\mathrm{G}=5.58 \times 10^{-4} \mathrm{~kg} / \mathrm{s}$.

Unit (with respect to sample damaged section area unit) $\operatorname{SPE}(\Delta \mathrm{m} / \Delta \mathrm{S})$ increases with air-abrasive flow rate $G$ rising. It should be noted that with flow rate rising weight loss $\Delta \mathrm{m}$ grows individually and the sample damaged section area $\mathrm{S}$ increases individually too.

The maximum value of mass loss $\Delta \mathrm{m}$ per unit area of the sample surface $\mathrm{S}$ for both types of steels is observed at attack angles closed to $30^{\circ}$. These data are correlated with the results obtained in the study of other structural materials [5-8]. 


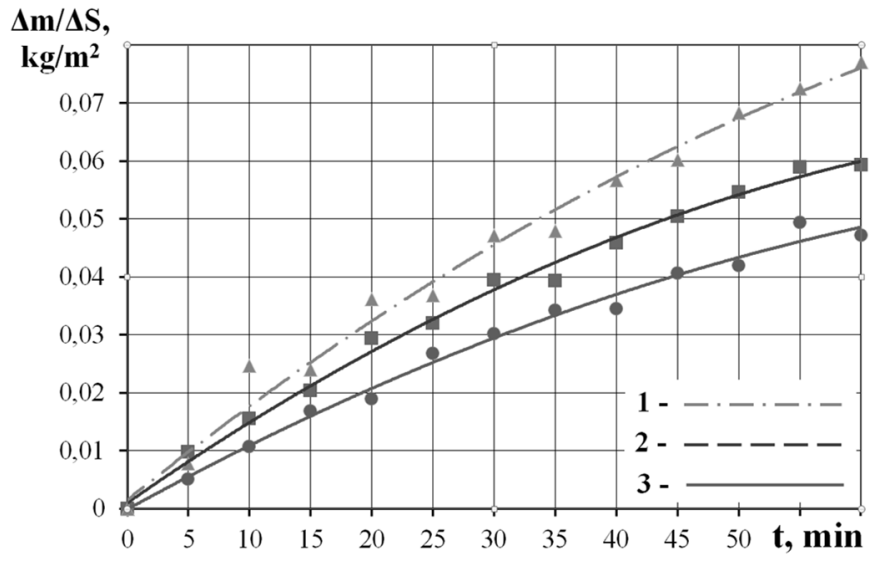

(a)

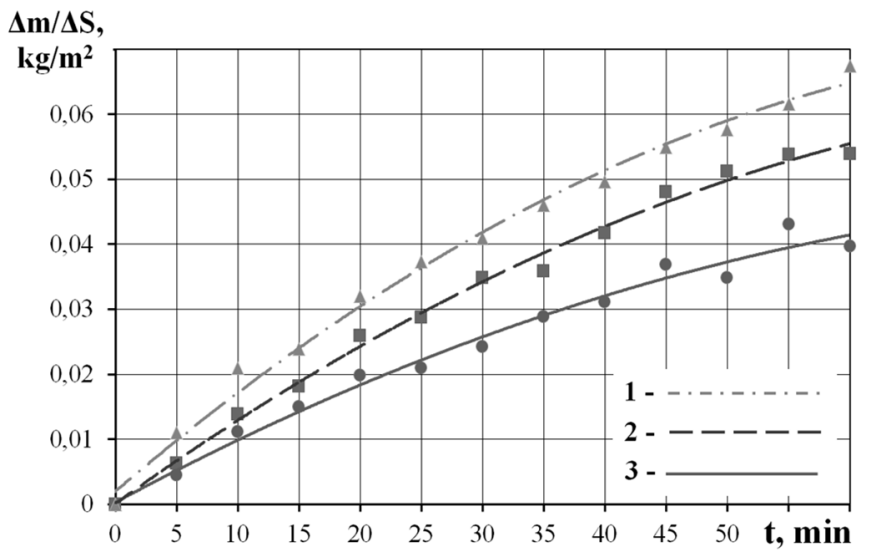

(b)

Figure 4: Air-abrasive flow rate influence on the SPE intensity $(\Delta \mathrm{m} / \Delta \mathrm{S})$ of steel $20 \mathrm{kH} 13$ (a) and steel $15 \mathrm{kH} 11 \mathrm{MF}$ (b) in attack angle of $30^{\circ}: 1-\mathrm{G}=$ $5.58 \times 10^{-4} \mathrm{~kg} / \mathrm{s} ; 2-\mathrm{G}=4.78 \times 10^{-4} \mathrm{~kg} / \mathrm{s} ; 3-\mathrm{G}=3.88 \times 10^{-4} \mathrm{~kg} / \mathrm{s}$. 


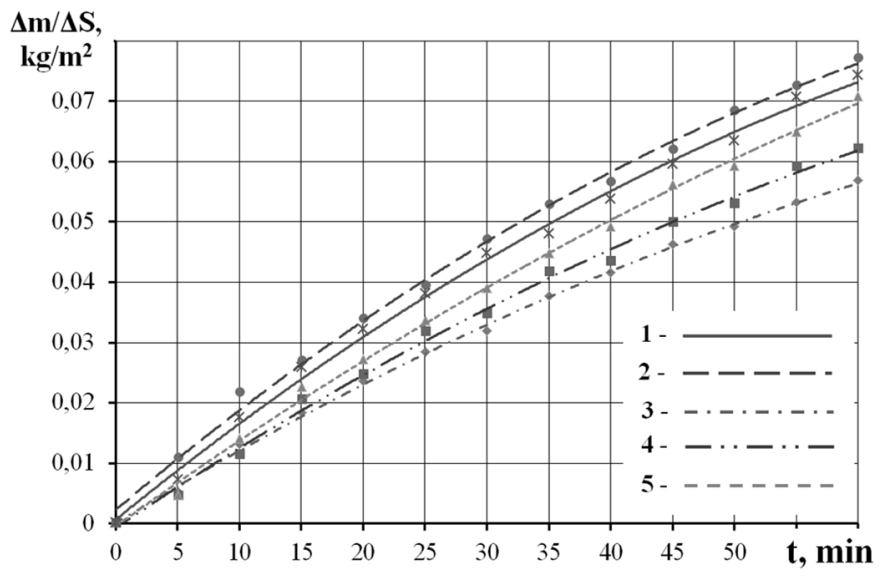

(a)

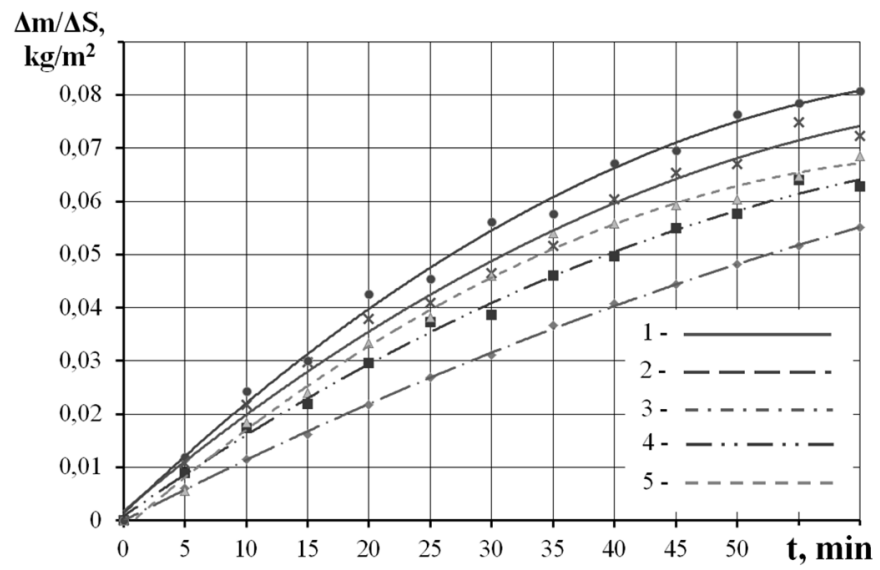

(b)

Figure 5: Dependence of unit SPE of steel 20kH13 (a) and steel 15kH11MF (b) on attack angle at air-abrasive flow rate $\mathrm{G}=5.58 \times 10^{-4} \mathrm{~kg} / \mathrm{sec}$ : $1-15^{\circ} ; 2-30^{\circ} ; 3-45^{\circ} ; 4-60^{\circ} ; 5-90^{\circ}$.

The investigation's results of experimental samples surface (for example, steel $15 \mathrm{kH} 11 \mathrm{MF}$ ) including the abrasive trace imaging, the sample surface profilograms construction in longitudinal and cross directions according to the scheme in Figure 3, and the maximum depth value of wear $h_{\text {imax }}$ are shown in Table 3 . 
Table 3: The SPE damage characteristic profilograms in the longitudinal and cross directions, maximum depth values $h_{\text {imax }}$ of SPE after samples research (test parameters: air-abrasive flow rate $\mathrm{G}=5.58 \times 10^{-4} \mathrm{~kg} / \mathrm{s}$, exposure time -60 minutes, the attack angle $\alpha=$ var).

\begin{tabular}{|c|c|c|c|c|c|}
\hline $\begin{array}{l}\text { Attack } \\
\text { angle } \\
\alpha, \text { deg. }\end{array}$ & $\begin{array}{l}\text { Trace } \\
\text { image }\end{array}$ & $\begin{array}{l}\text { Profile of abrasive } \\
\text { trace in the } \\
\text { longitudinal } \\
\text { direction }\end{array}$ & & $\begin{array}{l}\text { Profile of abrasive } \\
\text { trace in the cross } \\
\text { direction }\end{array}$ & $\begin{array}{c}\text { Depth } \\
\text { value } \\
\mathrm{h}_{\text {imax }}, \mu \mathrm{m}\end{array}$ \\
\hline 15 & & & $\mathbf{h}_{1}$ & $h_{1}$ & $67 \pm 0.05$ \\
\hline 30 & & & $h_{2}$ & $h_{2}$ & $90 \pm 0.05$ \\
\hline 45 & & & $\mathbf{h}_{3}$ & h & $105 \pm 0.05$ \\
\hline 60 & & & $\mathbf{h}_{4}$ & h & $100 \pm 0.05$ \\
\hline 90 & & & $h_{5}$ & h & $117 \pm 0.05$ \\
\hline
\end{tabular}

\section{Discussion of the results}

The results of conducted research show an extensive possibilities of rig in a comprehensive study of the various structural materials SPE process in a wide range of variable experiment parameters.

The intensity of SPE increases with the air-abrasive flow rate rising with the attack angle decreasing, and reaches its maximum value at attack angles close to $30^{\circ}$. 
The character of obtained dependences is identical for both types of steel, the SPE intensity of $15 \mathrm{kH1} 1 \mathrm{MF}$ steel lower than steel $20 \mathrm{kH13}$, but is in the experimental error range.

Based on these data planned the experimental research for SPE resistance and surfaces fracture dynamics of considered blade steels samples at high temperatures (up to $550^{\circ} \mathrm{C}$ ) corresponding to the operating conditions of the steam turbines HPC and MPC first stages blading.

\section{Acknowledgement}

The intermediate results obtained with the financial support of the Ministry of Education and Science of the Russian Federation as part of the agreement No. 14.574.21.0011 of 17 June 2014 (unique identification number RFMEFI57414H0011).

\section{References}

[1] A.B. Tkhabisimov, L.I. Seleznev, Statistical characteristics of the "target erodent" abrasion process of structural materials, Abstracts of the Twenty First International scientific-technical conference of students and postgraduates, February 26-27, 4, p. 133, 2015.

[2] A.V. Ryzhenkov, G.V. Kachalin, A.F. Mednikov, A.B. Tkhabisimov The investigation of construction materials and protective coatings wear resistance to solid particle erosion, Modern Applied Science; 9(4), pp. 85-95, 2015.

[3] J.R. Laguna-Camacho, A. Marquina-Chávez, J.V. Mendez-Mendez, M. ViteTorres, E.A. Gallardo-Hernandez, Solid particle erosion of AISI 304, 316 and 420 stainless steels, Wear, 301, pp. 1-8, 2013.

[4] E. Akbarzadeh, E. Elsaadawy, A.M. Sherik, J.K. Spelt, M. Papini, The solid particle erosion of 12 metals using magnetite erodent, Wear, 282-283, pp. 40$51,2012$.

[5] D. Aquaro and E. Fontani, Erosion of Ductile and Brittle Materials, Meccanica 36, pp. 651-661, 2001.

[6] A. Gnanavelu, N. Kapur, A. Neville, J.F. Flores, An integrated methodology for predicting material wear rates due to erosion, Wear, 267, pp. 1935-1944, 2009.

[7] S. Nsoesie, R. Liu, K.Y. Chen, M.X. Yao, Analytical modeling of solidparticle erosion of Stellite alloys in combination with experimental investigation, Wear, 309, pp. 226-232, 2014.

[8] A.A. Kopylov, Yu. G. Veksler, V.A. Styazhkin, S.Ya. Paleeva, A.N. Paderov, Vibration-Gas-Abrasive Wear Resistance of Turbine Compressor Blades, Zashchita Metallov, 2(36), pp. 189-191, 2000. 